\title{
Open Source Migration in Greek Public Sector: A Feasibility Study
}

\author{
Androklis Mavridis, Dimitrios Fotakidis, and Ioannis Stamelos \\ Software Engineering Group, Department of Informatics, \\ Aristotle University of Thessaloniki, Greece \\ Aristotle University Campus, PO Address 54124 \\ amavridis@csd.auth.gr, dfotakidis@yahoo.gr, stamelos@csd.auth.gr
}

\begin{abstract}
Open Source software has been recently recognized by governments as a viable and cost effective solution. However, transition to open source is not a plug-and-play process but one that requires deep knowledge of open source dynamics and of organization's operations, budgetary constraints, capacities, ethics and political agenda. As with any IT transition, there are uncertainties and risks that need to be handled in order to maximize the gains for the organization and for the society through the provided services. In this paper we present a feasibility study conducted in 15 Greek public sector organizations with the aim to discover the value this transition brings to a typical public sector organization.
\end{abstract}

\section{Introduction}

The benefits of Open Source Software (OSS) within public sector (PS) have been highlighted by numerous studies [6],[12],[14],[15] focusing on the the fast growth of OSS projects and open standards which offer usable solutions able to support organizations in supplying high quality services to society. However the OSS migration is not a risk free plug and play process. According to [3], the uncertainty of the quality of the OSS applications [4], the dynamic nature of the majority of OSS projects [5] and the lack of technical support [9] are some of the obstacles faced by integrators. Furthermore, while there is an acknowledged demand for financial transparency that advocates the use of OSS, there is still lack of awareness of the feasibility and viability of OSS in the PS environment. In [13] authors argue that the majority of public sector shows little interest in financial performance.

To discover the value of OSS migration and to shed light to the uncertainties that affect its viability, we conducted a feasibility study in fifteen municipalities in Greece, where we calculated the value generated from three scenarios of OSS adoption namely minimal, basic and massive based on the number and type of the adopted software solutions. To do so, Real Options Analysis was employed as a decision making tool able to capture the uncertainties faced by integrators and calculate their impact on the anticipated revenues.

The paper is structured as follows. In section two we provide background information on the Real Options Theory and tools, followed by the proposed 
approach. In section three we analytically present the results of the study and finally we share some ideas for further research in section four.

\section{Background and Proposed Approach}

We argue that the value of an OSS is generated and both affected by its project's dynamics [7]. As the OSS evolves over time, uncertainties related with its provided qualities such as usability, availability and maintainability, may be introduced or resolved. However, to what extend these uncertainties will affect the anticipated value is subject to organization's capacities, competencies, resources and constraints. Hence, selecting the right OSS solutions (the more profitable) depends on organization's resilience to these uncertainties. In this respect, finding the more profitable migration scenario is not simply a matter of accumulating the value generated from the number of OSS solutions to be adopted but of identifying which OSS solutions maximize and/or maintain their values over time.

Real options analysis is a valuable decision making tool capable of exploring the volatility of the anticipated OSS value in order to provide reasoning about the viability of the migration scenario. Real Options Analysis (ROA) is based on the analogy between investment opportunities and financial options. A real option is a right, but not an obligation, to make a decision for a certain cost within a specific time frame. A project is perceived as an option on the underlying cash flows (value) with multiple associated investment strategies to be exercised if conditions turned out to be favorable.

As option is an asset that provides its owner the right with out a symmetric obligation to make an investment decision such as growth, exit, wait, and learning etc. If conditions to investing arise, the owner can exercise the option by investing the strike price defined by the option. A call option gives the right to acquire an asset of uncertain future value for the strike price. There are two option mechanisms, namely the call and put.

A call option gives the buyer of the option the right to buy the underlying asset at a fixed price, called the exercise price, at any time prior to the expiration date of the option: the buyer pays a price for this right. If at expiration, the value of the asset is less than the strike price, the option is not exercised and expires worthless. If, on the other hand, the value of the asset is greater than the strike price, the option is exercised. The net profit on the investment is the difference between the gross profit and the price paid for the call initially.

In a similar manner, a put option gives the buyer of the option the right to sell the underlying asset at a fixed price, again called the strike or exercise price, at any time prior to the expiration date of the option. The buyer pays a price for this right. If the price of the underlying asset is greater than the strike price, the option will not be exercised and will expire worthless. If on the other hand, the price of the underlying asset is less than the strike price, the owner of the put option will exercise the option and sell the stock a the strike price, claiming the difference between the strike price and the market value of the asset as the gross profit.

Many authors appreciated the applicability of ROA in IT investments like in [1],[2] while others employed ROA in software engineering practices such as in 
$[8],[10],[11]$. Following the same logic, we argue that an OSS migration scenario can be expressed as a call option, where the owner (the PS organization) has the right but not the obligation to make the selection within a given time frame.

Before proceeding to the analysis we translate the traditional ROA variables to fit to our context of use. Intuitively we have:

1. Current Value (Net Present Value) of migration scenario (So): The accumulation of the costs of the operational proprietary software are the cash flows generated from the adopted OSS.

2. Exercise Price (X): Total Cost of Ownership (TCO) of the adopted OSS.

3. Time to Expiration (T): The time frame decision makers have to select the optimum migration scenario.

4. Volatility of the Underlying Asset Value $(\sigma)$ : The percentage of the cash flows fluctuations due to uncertainties introduced from the dynamics of the adopted OSS.

5. Risk Rate (r): The Cost of capital

Our approach employs three consecutive steps. The first step commences with the discovery of the uncertainties. In the second we calculate the expected cash flows and their associated volatilities in the form of (\%) standard deviation, and finally in the third step we calculate the call options for each OSS candidate and we compare the results. We present this steps in detail through our presentation of the case study.

\section{Feasibility Study on the Migration to OSS in Greek Public Sector}

\subsection{Study Preparation}

We examined 85 of the 325 (26.15\%) municipalities in Greece where we recorded all proprietary applications currently in use and categorized these according to their provided functionalities and domain:

- Administrative Applications

- Office related Applications

- Resource Planning Applications

- Operating System

After conducting interviews with IT managers we produced a list of OSS applications capable of providing the intended functionalities and group these into three migration scenarios as shown in table 1:

$>$ Scenario 1 - Massive Change

$>$ Scenario 2 - Basic change

$>$ Scenario 3 - Minimal change 
Table 1. OSS applications capable of substituting the currently installed closed source applications

\begin{tabular}{|c|c|c|c|}
\hline SOFTWARE & SCENARIO 1 & SCENARIO 2 & SCENARIO 3 \\
\hline Office Application & OpenOffice.org & OpenOffice.org & OpenOffice.org \\
\hline Operating System & UBUNTU LINUX & - & - \\
\hline Protocol & \multirow{2}{*}{ SCRIPTUM } & \multirow{2}{*}{ SCRIPTUM } & \multirow{2}{*}{ SCRIPTUM } \\
\hline Document Management & & & \\
\hline Registries Managment & \multirow{5}{*}{ OpenERP } & \multirow{5}{*}{ OpenERP } & \multirow{5}{*}{-} \\
\hline Real Estate Tax & & & \\
\hline Traffic code & & & \\
\hline Water/Sewer & & & \\
\hline Irrigation & & & \\
\hline Payroll & \multirow[b]{2}{*}{ OrangeHRM } & \multirow[b]{2}{*}{ OrangeHRM } & \\
\hline $\begin{array}{l}\text { Humman Resource } \\
\text { Management (HRM) }\end{array}$ & & & \\
\hline
\end{tabular}

We then proceeded to a closer examination of fifteen municipalities (average in population size and in IT department staffing), to obtain the necessary financial data for our ROA application. For each scenario we calculated the installation and maintenance costs as shown below (all calculations are in Euros):

Table 2. Installation and Maintenance costs for scenario 1

\begin{tabular}{|l|r|r|r|r|}
\hline OSS Software & Installation Cost & Maintenance Cost & Total & \\
\hline Open Office & 2,000 & 0 & 2,000 \\
\hline SCRIPTUM & 12,000 & 5,000 & 17,000 \\
\hline LinuX & 11,000 & 5,000 & 16,000 \\
\hline ERP & 15,000 & 5,000 & 20,000 \\
\hline OrangeHRM & 15,000 & 5,000 & 20,000 \\
\hline Total & $\mathbf{5 5 , 0 0 0}$ & $\mathbf{2 0 , 0 0 0}$ & $\mathbf{7 5 , 0 0 0}$ \\
\hline
\end{tabular}

Table 3. Installation and Maintenance costs for scenario 2

\begin{tabular}{|l|r|r|r|}
\hline OSS Software & Installation Cost & Maintenance Cost & Total \\
\hline Open Office & 2,000 & 0 & 2,000 \\
\hline SCRIPTUM & 12,000 & 5,000 & 17,000 \\
\hline ERP & 15,000 & 5,000 & 20,000 \\
\hline OrangeHRM & 15,000 & 5,000 & 20,000 \\
\hline Total & $\mathbf{4 4 , 0 0 0}$ & $\mathbf{1 5 , 0 0 0}$ & $\mathbf{5 9 , 0 0 0}$ \\
\hline
\end{tabular}

Table 4. Installation and Maintenance costs for scenario 3

\begin{tabular}{|l|r|r|r|r|}
\hline & & & & \\
OSS Software & Installation Cost & Maintenance Cost & Total & \\
\hline Open Office & 2,000 & 0 & 2,000 \\
\hline SCRIPTUM & 12,000 & 5,000 & 17,000 \\
\hline Total & 14,000 & $\mathbf{5 , 0 0 0}$ & $\mathbf{1 9 , 0 0 0}$ \\
\hline
\end{tabular}


We proceeded with calculation of costs of the currently operational proprietary software for a twenty years period. As stated before, these costs will be attributed to the cash flows generated from the adopted OSS. Similarly for each scenario we have:

Table 5. Cash flows from migration scenario 1

\begin{tabular}{|c|c|c|c|}
\hline Years & $\begin{array}{c}\text { Proprietary } \\
\text { Purchase Cost }\end{array}$ & $\begin{array}{c}\text { Installation and } \\
\text { maintenance cost }\end{array}$ & Total \\
\hline 2011 & $103,500.00$ & $32,500.00$ & $136,000.00$ \\
\hline 2012 & 0.00 & $34,125.00$ & $34,125.00$ \\
\hline 2013 & 0.00 & $35,831.25$ & $35,831.25$ \\
\hline 2014 & $36,225.00$ & $37,622.81$ & $73,847.81$ \\
\hline 2015 & 0.00 & $39,503.95$ & $39,503.95$ \\
\hline 2016 & 0.00 & $41,479.15$ & $41,479.15$ \\
\hline 2017 & $38,036.25$ & $43,553.11$ & $81,589.36$ \\
\hline 2018 & 0.00 & $45,730.76$ & $45,730.76$ \\
\hline 2019 & 0.00 & $48,017.30$ & $48,017.30$ \\
\hline 2020 & $39,938.06$ & $50,418.17$ & $90,356.23$ \\
\hline 2021 & 0.00 & $52,939.08$ & $52,939.08$ \\
\hline 2022 & 0.00 & $55,586.03$ & $55,586.03$ \\
\hline 2023 & $41,934.97$ & $58,365.33$ & $100,300.30$ \\
\hline 2024 & 0.00 & $61,283.60$ & $61,283.60$ \\
\hline 2025 & 0.00 & $64,347.78$ & $64,347.78$ \\
\hline 2026 & $44,031.71$ & $67,565.17$ & $111,596.88$ \\
\hline 2027 & 0.00 & $70,943.42$ & $70,943.42$ \\
\hline 2028 & 0.00 & $74,490.60$ & $74,490.60$ \\
\hline 2029 & $46,233.30$ & $78,215.13$ & $124,448.42$ \\
\hline 2030 & 0.00 & $82,125.88$ & $82,125.88$ \\
\hline Total & $349,899.29$ & $1,074,643.51$ & $1,424,542.80$ \\
\hline
\end{tabular}


Table 6. Cash flows from migration scenario 2

\begin{tabular}{|c|c|c|c|}
\hline Years & $\begin{array}{c}\text { Proprietary Purchase } \\
\text { Cost }\end{array}$ & $\begin{array}{c}\text { Installation and } \\
\text { maintenance cost }\end{array}$ & Total \\
\hline 2011 & $98,500.00$ & $28,500.00$ & $127,000.00$ \\
\hline 2012 & 0.00 & $29,925.00$ & $29,925.00$ \\
\hline 2013 & 0.00 & $31,421.25$ & $31,421.25$ \\
\hline 2014 & $34,475.00$ & $32,992.31$ & $67,467.31$ \\
\hline 2015 & 0.00 & $34,641.93$ & $34,641.93$ \\
\hline 2016 & 0.00 & $36,374.02$ & $36,374.02$ \\
\hline 2017 & $36,198.75$ & $38,192.73$ & $74,391.48$ \\
\hline 2018 & 0.00 & $40,102.36$ & $40,102.36$ \\
\hline 2019 & 0.00 & $42,107.48$ & $42,107.48$ \\
\hline 2020 & $38,008.69$ & $44,212.85$ & $82,221.54$ \\
\hline 2021 & 0.00 & $46,423.50$ & $46,423.50$ \\
\hline 2022 & 0.00 & $48,744.67$ & $48,744.67$ \\
\hline 2023 & $39,909.12$ & $51,181.91$ & $91,091.03$ \\
\hline 2024 & 0.00 & $53,741.00$ & $53,741.00$ \\
\hline 2025 & 0.00 & $56,428.05$ & $56,428.05$ \\
\hline 2026 & $41,904.58$ & $59,249.45$ & $101,154.03$ \\
\hline 2027 & 0.00 & $62,211.93$ & $62,211.93$ \\
\hline 2028 & 0.00 & $65,322.52$ & $65,322.52$ \\
\hline 2029 & $43,999.81$ & $68,588.65$ & $112,588.46$ \\
\hline 2030 & 0.00 & $72,018.08$ & $72,018.08$ \\
\hline Total & $332,995.94$ & & \\
\hline
\end{tabular}


Table 7. Cash flows from migration scenario 3

\begin{tabular}{|c|c|c|c|}
\hline Years & $\begin{array}{l}\text { Proprietary Purchase } \\
\text { Cost }\end{array}$ & $\begin{array}{l}\text { Installation and } \\
\text { maintenance cost }\end{array}$ & Total \\
\hline 2011 & $18,500.00$ & $10,000.00$ & $28,500.00$ \\
\hline 2012 & 0.00 & $10,500.00$ & $10,500.00$ \\
\hline 2013 & 0.00 & $11,025.00$ & $11,025.00$ \\
\hline 2014 & $6,475.00$ & $11,576.25$ & $18,051.25$ \\
\hline 2015 & 0.00 & $12,155.06$ & $12,155.06$ \\
\hline 2016 & 0.00 & $12,762.82$ & $12,762.82$ \\
\hline 2017 & $6,798.75$ & $13,400.96$ & $20,199.71$ \\
\hline 2018 & 0.00 & $14,071.00$ & $14,071.00$ \\
\hline 2019 & 0.00 & $14,774.55$ & $14,774.55$ \\
\hline 2020 & $7,138.69$ & $15,513.28$ & $22,651.97$ \\
\hline 2021 & 0.00 & $16,288.95$ & $16,288.95$ \\
\hline 2022 & 0.00 & $17,103.39$ & $17,103.39$ \\
\hline 2023 & $7,495.62$ & $17,958.56$ & $25,454.19$ \\
\hline 2024 & 0.00 & $18,856.49$ & $18,856.49$ \\
\hline 2025 & 0.00 & $19,799.32$ & $19,799.32$ \\
\hline 2026 & $7,870.40$ & $20,789.28$ & $28,659.68$ \\
\hline 2027 & 0.00 & $21,828.75$ & $21,828.75$ \\
\hline 2028 & 0.00 & $22,920.18$ & $22,920.18$ \\
\hline 2029 & $8,263.92$ & $24,066.19$ & $32,330.12$ \\
\hline 2030 & 0.00 & $25,269.50$ & $25,269.50$ \\
\hline Total & $62,542.39$ & $330,659.54$ & $393,201.93$ \\
\hline
\end{tabular}

\subsection{Applying Real Options Analysis}

From the collected information we where able to calculate the total budget assuming a two year period within which all employees will operate the adopted OSS solutions: 


\begin{tabular}{|c|c|c|}
\hline \multicolumn{3}{|c|}{ Total Budget } \\
\hline Scenario 1 & Scenario 2 & Scenario 3 \\
\hline 99,850 & 80,550 & 24.700 \\
\hline
\end{tabular}

Finally the Net Present Values with 10\% cost of capital was found:

\begin{tabular}{|c|c|c|}
\hline \multicolumn{3}{|c|}{ Net Present Value } \\
\hline Scenario 1 & Scenario 2 & Scenario 3 \\
\hline 134,001 & 169,445 & 42,199 \\
\hline
\end{tabular}

To estimate the volatilities we took into account the following factors affecting the expected cash flows for each scenario:

A Popularity of the OSS to be adopted

A Awareness of the OSS from employees

A Dependency of the substituted proprietary application with legacy applications

Based on the scores and weights provided by the IT managers we obtained a $30 \%$, $20 \%$ and $10 \%$ volatility estimations for the three scenarios respectively.

With risk rate at $10 \%$ and Time to expiration 4 years (the time frame to select one of the three scenarios) we have:

Table 8. Data for ROA - scenario 1

\begin{tabular}{|l|c|}
\hline Net Present Value & $134,151.08$ \\
\hline Exercise Price & $99.850,00$ \\
\hline Time to Option Expiration & 4 Years \\
\hline Risk rate & $10,00 \%$ \\
\hline Volatility & $30,00 \%$ \\
\hline
\end{tabular}

Table 9. Data for ROA - scenario 2

\begin{tabular}{|l|c|}
\hline Net Present Value & $169,445.39 €$ \\
\hline Exercise Price & $80.550,00 €$ \\
\hline Time to Option Expiration & 4 Years \\
\hline Risk rate & $10,00 \%$ \\
\hline Volatility & $20,00 \%$ \\
\hline
\end{tabular}

Table 10. Data for ROA - scenario 3

\begin{tabular}{|l|c|}
\hline Net Present Value & $42,20 €$ \\
\hline Exercise Price & $24.700,00 €$ \\
\hline Time to Option Expiration & 4 Years \\
\hline Risk rate & $10,00 \%$ \\
\hline Volatility & $10,00 \%$ \\
\hline
\end{tabular}


To calculate the Option Values $\mathrm{C}_{0}$ we employed the Black-Scholes model given as :

$$
\mathrm{C}_{0}=\mathrm{S}_{0} \mathrm{~N}\left(\mathrm{~d}_{1}\right)-\mathrm{Xe}^{-\mathrm{rT}} \mathrm{N}\left(\mathrm{d}_{2}\right)
$$

where:

$$
\begin{aligned}
& \mathrm{d}_{1}=\left[\ln \left(\mathrm{S}_{0} / \mathrm{X}\right)+\left(\mathrm{r}+\sigma^{2} / 2\right) \mathrm{T}\right] / \sigma \sqrt{ } \mathrm{T}, \\
& \mathrm{d}_{2}=\mathrm{d}_{1}-\sigma \sqrt{\mathrm{T}},
\end{aligned}
$$

and $\mathrm{N}(\mathrm{d})$ is the probability that a random draw from a standard normal distribution will be less than (d). Employing available Option Value calculators ${ }^{1}$ we finally obtained:

\begin{tabular}{|c|c|c|}
\hline \multicolumn{3}{|c|}{ Options Values } \\
\hline Scenario 1 & Scenario 2 & Scenario 3 \\
\hline 70,845.18 & $115,471.65$ & $25,642.09$ \\
\hline
\end{tabular}

These option values represent the additional value that comes from the right not to implement immediately the migration scenario but only upon favorable conditions. Going a step further Option Value $\mathrm{C}_{0}$ depends on two variables, the Intrinsic Value (IV) and the Time Value (TV), as such,

$$
\mathrm{C}_{0}=\mathrm{IV}+\mathrm{TV}
$$

The intrinsic value (IV) of an option is the value of the option if exercising it now and is given as:

$$
\mathrm{IV}=\mathrm{S}_{0}-\mathrm{X}
$$

Intrinsic value can be defined as the amount by which the exercise price of an option is "in-the-money". It is actually the portion of an option's price that is not lost due to the passage of time. While Time Value or "Option Premium" give as:

$$
\mathrm{TV}=\mathrm{OV}-\mathrm{IV}
$$

is the real cost of owning a stock options contract. It is the part of the price of an option which the seller of the option gets to keep as profit should the stock remain inactive until its expiration. In our context Time Value is the amount of money the PS organization will loose by waiting to see how the uncertainties associated with the migration scenario will evolve over the time to expiration. Calculating the option premiums for the three scenarios we have:

\footnotetext{
${ }^{1}$ http: //www.soarcorp.com/black_scholes_calculator.j.sp
} 


\begin{tabular}{|l|c|}
\cline { 2 - 2 } \multicolumn{1}{c|}{} & Option Premium \\
\hline Scenario 1 & $36,694.10$ \\
\hline Scenario 2 & $26,576.26$ \\
\hline Scenario 3 & $8,143.09$ \\
\hline
\end{tabular}

What we can infer is that the third scenario is the one with the lowest cost of waiting. Nevertheless, the second scenario is the one that should be preferred as not only provides the highest Net Present Value but also a lower cost of waiting (option premium) in comparison to the first scenario.

\section{Conclusions}

We have presented an options based approach for the valuation of the OSS migration in a PS organization. The application of ROA addresses some fundamental issues, like the lack of accountability and risk averseness inherent in PS environments. The method provides an alternative view to the OSS migration process in the uncertain Open Source Software realm. By perceiving the OSS migration as a risky investment, a more accurate calculation of the anticipated value of OSS employment to PS environments can be achieved. It is our intention to extend this study to other public sector organizations and to examine the suitability and applicability of simulation techniques i.e. Monte-Carlo in volatility calculations.

\section{References}

[1] Amram, M., Kulatilaka, N.: Real Options: Managing Strategic Investment in an Uncertain World. Harvard Business School Press, Boston (1999)

[2] Erdogmus, H.: Valuation of Learning Options in Software Devel- opment under Private and Market Risk. The Engineering Economist 47(3), 308-353 (2002)

[3] Gosh, R.A., Glott, R., Schmitz, P.E., Boujraf, A.: OSOR Guide- lines, Public procurement and Open Source Software. Public draft version 1.0. Unisys Belgium, UNU-MERIT (2008)

[4] Immonen, A., Palviainen, M.: Trustworthiness Evaluation and Testing of Open Source Applications. In: Seventh International Conference on Quality Software (QSIC 2007), Portland, Oregon, USA (October 2007)

[5] Immonen, A., Palviainen, M.: Trustworthiness Evaluation and Testing of Open Source Applications. In: Seventh International Conference on Quality Software (QSIC 2007), Portland, Oregon, USA (October 2007)

[6] Kovacs, G.L., Drozdik, S., Zuliani, P., Succi, G.: Open source software for the public administration. In: Proceedings of the 6th International Workshop on Computer Science and Information Technologies, Budapest, Hungary (2004)

[7] Mavridis, A., Stamelos, I.: Real Options as tool enhancing Rational of OSS applications selection. In: IEEE-DEST 2009, Istanbul, Turkey, May 31-June 2 (2009)

[8] Ozkaya, I., Kazman, R., Klein, M.: Quality-Attribute Based Economic Valuation of Architectural Patterns, Technical Report CMU/SEI CMU/SEI-2007-TR-003 (2007) 
[9] Singh, V., Twidale, B.M., Nichols, D.M.: Users of Open Source Software - How do they get help? In: Proceedings of the 42nd Hawaii International Conference on System Sciences, Hawaii, January 5-8 (2009)

[10] Shaw, M., Arora, A., Butler, S., Poladian, V., Scaffidi, C.: In search of a unified theory for early predictive design evaluation for software, Technical Reports CMU-ISRI-05- 114, Carnegie Mellon University (2005)

[11] Sullivan, K.J., Chalasani, P., Jha, S., Sazawal, V.: Software Design as an Investment Activity: A Real Options Perspective. In: Trigeorgis, L. (ed.) Real Options and Business Strategy: Applications to Decision Making. Risk Books (1999)

[12] Richter, D., Zo, H., Maruschke, M.: A Comparative Analysis of Open Source Software Usage in Germany, Brazil, and India. In: Fourth International Conference on Computer Sciences and Convergence Information Technology, Seoul, Korea, November 24-26 (2009)

[13] Van Der Wal, Z., Huberts, L., Van Den Heuvel, H., Kolthoff, E.W.: Central Values of Government and Business: Differences, Similarities and Conflicts. Public Administration Quarterly 30(3), 314 (2006)

[14] Waring, T., Maddocks, P.: Open source software implementation in the UK public sector: evidence from the field and implications for the future. International Journal of Information Management 25, 411-428 (2005)

[15] Wong, K.: Free/Open Source Software: Government Policy. In: Asia- Pacific Development Information Programme e-Primers on Free/Open Source Software, UNDP-APDIP (2004) 